\title{
Family of a Patient with Serum Cholinesterase Deficiency
}

\author{
Masaki Ohara, Mamoru Hrrohata, Tsukasa Toshimori, Hiroyuki Miyatani, Ryoichi Okamoto, \\ Shoji Hirasaki, Hirofumi Kumashiro, Hiroki Moritani, Yokoh Tominaga and Masanobu ImaI
}

\begin{abstract}
A-39-year-old man was admitted to our hospital because of a markedly decreased level of serum cholinesterase found incidentally by a blood test. Detailed examination did not reveal severe liver disease, malignant tumor, infection or organophosphate compound poisoning. Investigation of three generations of his family revealed two homozygous and five heterozygous family members with the cholinesterase deficiency gene $\mathrm{E}_{1}{ }^{\mathrm{s}}$ indicating familial serum cholinesterase deficiency.
\end{abstract}

(Internal Medicine 31: 397-399, 1992)

Key words: pseudocholinesterase, succinylcholine, dibucaine number, fluoride number

\section{Introduction}

The clinical presentation of a patient with absent plasma cholinesterase was first described by Liddell et al (1) in 1962. In Japan, Shibata et al (2) first reported this disorder in 1967. This disease has clinical relevance, because the patient can develop prolonged apnea following administration of succinylcholine (SCC) (3-7). Here, we report a family with decreased $\mathrm{PsChE}$, which was identified incidentally at the department of neurology.

\section{Case Report}

A 39-year-old man was admitted to our hospital because of a decreased level of pseudocholinesterase (PsChE). His younger brother had diabetes mellitus. This patient underwent surgery for acute appendicitis under lumbar anesthesia with no particular problems. $\mathrm{He}$ had no previous history of general anesthesia or of diseases including organophosphate compound poisoning, severe liver disease or malignant tumor. In September 1988, the patient visited the department of neurology of our hospital because of irritability, and was found to have an unusually low level of pseudocholinesterase. No remarkable findings were observed on physical examination. Results of laboratory findings on admission were as follows: blood biochemistry revealed an unusually low level of PsChE $0.00 \Delta \mathrm{pH}$ (normal value, $0.80-1.10$ $\Delta \mathrm{pH}$ ), while the results of other blood tests, including liver function tests, were all normal. The liver was also found to be normal on both ultrasonography and computed tomography.

As the patient showed no abnormal findings other than an extremely low level of PsChE, nine members of three generations of his family were examined for suspected PsChE deficiency. The examination included: 1) determination of PsChE activity using the substrates benzolcholine $(\mathrm{BzCh})$ (normal value, $0.8-1.10 \Delta \mathrm{pH}$ ) and butylthiocholine (BtSCh) (normal value, $180-260 \mu$ $\mathrm{M} / \mathrm{ml} / \mathrm{h}$ ); 2) PsChE inhibition test by determining the dibucaine number (DN) and fluoride number (FN) according to the method of Iuchi and Ameno (3) (normal values: $\mathrm{DN}, 77-96 \%$; $\mathrm{FN}, 55-81 \%$ ); and 3) PsChE isozyme analysis using polyacrylamide gel.

Figure 1 shows the results of the determination of PsChE activity and PsChE inhibition tests together with the family tree. No abnormalities were found in any of the subjects on physical examination or blood biochemistry tests except for a reduced PsChE level, and none of them had a previous history of disorders responsible for decreased PsChE level. In the propositus (II-3) and his elder sister (II-1), PsChE was below the lowest measurable levels. His father (I-1), wife (II-2) and three children (III-1, 2, 3) also exhibited decreased PsChE activity. PsChE isozyme analysis showed no band of cholinesterase in the propositus or in his elder sister, who had an extremely low level of PsChE. Furthermore, the $\mathrm{C}_{5}$ component was not found in any of the subjects.

From the Department of Internal Medicine, Mitoyo General Hospital, Kagawa

Received for publication March 5, 1991; Acceptcd for publication Scptember 12, 1991

Reprint requests should be addressed to Masaki Ohara, M.D., the Department of Internal Medicine, Mitoyo General Hospital, 708 Himehama Toyohama-cho, Kagawa 769-16, Japan 


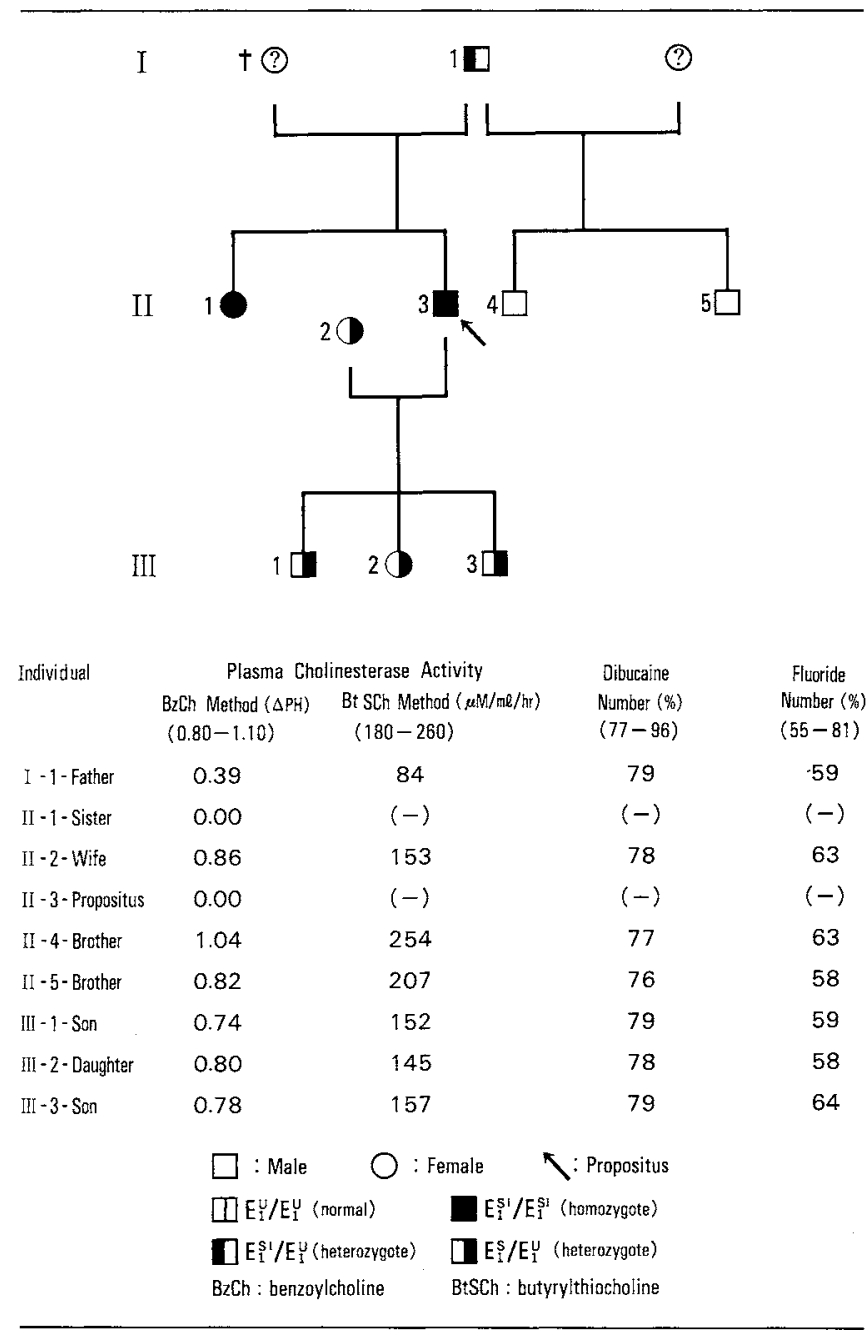

Fig. 1. The family of the propositus with serum cholinesterase deficiency.

\section{Discussion}

Cholinesterase is a choline ester hydrolyzing enzyme that is classified as PsChE when present in the serum and liver, and true cholinesterase when present in the erythrocytes, nerve tissues and muscles $(8,9)$. PsChE, which is frequently used as a parameter of protein synthesis in the liver, is decreased in disorders such as severe liver disease, organophosphate compound poisoning, malignant tumor and cachexia. Hereditary PsChE abnormality should be suspected in patients who do not have any of the above underlying diseases. With respect to the genetic dominance for PsChE, the $\mathrm{E}_{1}$ and $\mathrm{E}_{2}$ loci are thought to be located on autosomes (10). The $E_{1}$ locus has four types of genes: $E_{1}^{u}$, which controls the normal enzyme, and the alleles $\mathrm{E}_{1}^{\text {a }}$ (atypical; dibucaineresistant), $\mathrm{E}_{1}^{\mathrm{f}}$ (fluoride-resistant), and $\mathrm{E}_{1}^{\mathrm{s}}$ (silent), which cause deficits of enzyme activity. In $E_{1}$, includes also $E_{1}^{S I}$ with no enzyme activity and $E_{1}^{S 11}$ with an activity level that is only several percent of normal $(6,11)$. The $E_{2}$ locus, the presence of which was assumed on the basis of the results of PsChE isozyme analysis, is reportedly associated with the $\mathrm{C}_{5}$ component (12).

In this patient's family, the propositus and his elder sister were considered to be of the homozygous silent type $\left(\mathrm{E}_{1}^{\mathrm{sI}} / \mathrm{E}_{1}^{\mathrm{SI}}\right)$ because they completely lacked PsChE activity and no bands were observed in the PsChE isozyme analysis. His father, wife and children were thought to be heterozygous $\left(E_{1}^{s} / E_{1}^{u}\right)$ on the basis of normal findings for $\mathrm{DN}$ and $\mathrm{FN}$, despite a decreased PsChE activity.

The distribution of fluoride and dibucaine numbers has been measured in many different populations, to estimate the frequency of the atypical and fluoride-resistant alleles. Analysis of data (13) has shown that the atypical allele appears at a relatively high frequency in European populations (about 0.02 for a collective sample from several countries), but it is practically absent in Black and Oriental populations. In Japan, only about 20 cases of serum PsChE deficiency have been reported (2, $3,14)$. A few surveys of PsChE anomaly in Japan have been carried out (15). A total of 7,647 individuals have been screened and ten families with the phenotypes $\mathrm{E}_{1}^{\mathrm{u} /}$ $E_{1}^{\mathrm{a}}$ or $\mathrm{E}_{1}^{\mathrm{u}} / \mathrm{E}_{1}^{\mathrm{f}}$ have been detected, giving an approximate frequency of 0.0018 . This result is consistent with the previous conjecture of the extreme rarity of abberant PsChE genes in Japan.

Acknowledgments: The authors are deeply grateful to Prof. Iwao Iuchi and Dr. Kazuo Hidaka of the Department of Biochemistry, Kawasaki Medical School, for conducting serum analyses and for their helpful advice, and to Dr. Shigeru Morichika of the Fukuyama Municipal Hospital for his kind cooperation.

\section{References}

1) Liddell J, Lehmann H, Silk E. A silent pseudocholinesterase gene. Nature 193: 561, 1962.

2) Shibata S, Iuchi I, Hashimoto Y, Shoda T. A consanguineous kindred of serum psudocholinesterase anomaly found in Japan. Proc Japan Acad 43: 907, 1967.

3) Iuchi I, Ameno S. Survey of atypical serum cholinesterase in Okayama district (preliminary report) and a new method for its detection. J Kawasaki Hosp 2: 97, 1969 (in Japanese).

4) Bourne JG, Collier HO, Somers GF. Succinylcholine; muscle relaxant of short action. Lancet 1: 1225, 1952.

5) Evans FT, Gray PWS, Lehmann H, Silk E. Sensitivity to succinylcholine in relation to serum cholinesterase. Lancet 1: 1229, 1952.

6) Kalow W, Genest K. A method for the detection of atypical forms of human serum cholinesterase; determination of dibucaine numbers. Can J Biochem Physiol 35: 339, 1957.

7) Kalow W, Staron N. On distribution and inheritance of atypical forms of human serum cholinesterase, as indicated by dibucaine number. Can J Biochem Physiol 35: 1305, 1957.

8) Alles GA, Hawes RC. Cholinesterases in blood of man. J Biol Chem 133: 375, 1940.

9) Mendel B, Rundney H. Studies on cholinesterase; cholinesterase and pseudocholinesterase. Biochem J 37: 59, 1943. 


\section{Serum Cholinesterase Deficiency}

10) Harris RH, Hopkinson DA, Robson EB. Two-dimensional electrophoresis of pseudocholinesterase components in normal human serum. Nature 196: 1296, 1962.

11) Harris $H$, Whittaker $M$. Differential inhibition of human cholinesterase with fluoride: Recognition of two phenotypes. Nature 191: $1496,1961$.

12) Harris H. Differential inhibition of "usual" and "atypical" serum cholinesterase by sodium chloride and sodium fluoride. Ann
Hum Genet 27: 53, 1963.

13) Whittaker M. Cholinesterase Monographs in Human Genetics. Vol. 11. 45, 1986.

14) Miyamoto $M$, Masukawa $A$, Ochiai $A$, et al. A case with silent type of pseudo-acholinesteransemia. Tokai J Clin Med 12: 365 , 1987.

15) Iuchi I. Abnormal psudocholinesterase. Jpn J Human Genet 27: 95, 1982. 